\title{
Experimental Study and Measures on Engineering Characteristics of Diatomite Subgrade in Shengzhou
}

\author{
Han Jianwen \\ China Railway Design Corporation, Tianjin, China
}

Email address:

15122017014@139.com

\section{To cite this article:}

Han Jianwen. Experimental Study and Measures on Engineering Characteristics of Diatomite Subgrade in Shengzhou. American Journal of Traffic and Transportation Engineering. Vol. 6, No. 3, 2021, pp. 95-106. doi: 10.11648/j.ajtte.20210603.14

Received: May 11, 2021; Accepted: May 27, 2021; Published: June 26, 2021

\begin{abstract}
This paper takes the newly built railway passing through the diatom land area of Shengzhou and Xinchang in Zhejiang Province as an example. And based on the field test of soil samples, this paper pointed out that due to low natural density, large void ratio, high water content, dry shrinkage and wet expansion, relative deformation and strength, The diatomite are not suitable to be directly used as building foundation. Based on the static load of single pile, bearing capacity of composite foundation and in-situ vibration test of foundation bed, it proposed that CFG pile, plain concrete pile and reinforced concrete pile are suitable for diatomite foundation reinforcement. While screw pile has insufficient bearing capacity, due to soil compaction effect and poor pile forming effect of high pressure jet grouting pile. CFG and plain concrete pile composite foundation can meet the requirements of diatomite subgrade deformation, and plain concrete pile is much better. The raft structure has better integrity. The capillary waterproof and drainage board can significantly improve the waterproof and drainage effect, and reduce the adverse effect of dynamic load on diatom soil foundation. Based on the slope rainfall test, it is proposed that diatomite natural slope is easy to form network cracks and induce shallow landslide under the action of dry wet cycle. In addition, the effect of gentle slope and skeleton on Diatomite slope is better.
\end{abstract}

Keywords: Shengzhou, Zhejiang Province, Railway Subgrade, Diatomite, Field Test, Composite Foundation, Slope Protection, Waterproof and Drainage Subgrade Bed

\section{Introduction}

Diatomite is a kind of silicate remains of unicellular algae collectively referred to as diatoms, deposit formed by the accumulation period of about 10000 to 20000 years, which is mainly distributed in China, the United States, Denmark, France, Romania and other countries. In China, it is mainly distributed in Jilin, Zhejiang, Yunnan, Shandong, Sichuan and other provinces. Diatomite from different sources has different compositions. The main mineral compositions are opal and its varieties, followed by clay minerals hydromica, kaolinite and mineral debris. Its chemical composition is mainly $\mathrm{SiO}_{2}$, the rest is a small amount of $\mathrm{Al}_{2} \mathrm{O}_{3}, \mathrm{Fe}_{2} \mathrm{O}_{3}, \mathrm{CaO}$, $\mathrm{MgO}$ and organic matter. Its color depends on the clay minerals and organic matter. Single diatom is colorless and transparent, high-quality diatomite is white, and its $\mathrm{SiO}_{2}$ content often exceeds 70\%. Mineral clasts include quartz, feldspar, biotite and organic matter. Its density about $1.9-2.3 \mathrm{~g} / \mathrm{cm}^{3}$, Bulk density about $0.34-0.65 \mathrm{~g} / \mathrm{cm}^{3}$, Specific surface area about 40-65 $\mathrm{m}^{2} / \mathrm{g}$, Pore volume about $0.45-0.98 \mathrm{~cm}^{3} / \mathrm{g}$, The water absorption is $2-4$ times of its own volume, and it has the properties of fine, loose, light weight, porous, water absorption and permeability, and is an excellent industrial raw material and decoration auxiliary material.

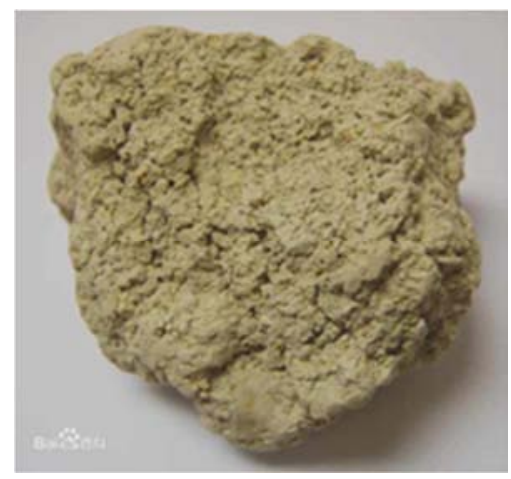




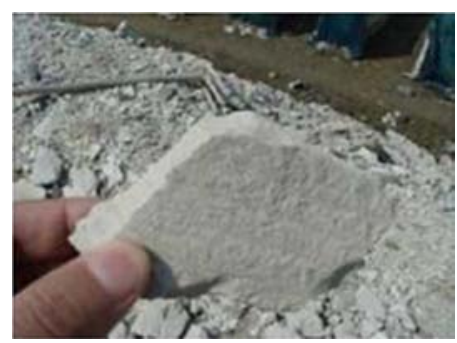

Figure 1. Diatomite in Natural State.

The characteristics of diatomite, such as high sensitivity, strong expansion and shrinkage and porous structure, may bring many hidden dangers to the construction projects in the area, such as slope stability and foundation settlement. After consulting, there are few theories and experiences in large-scale engineering construction based on diatom land.

Zhang yongshuang [1, 3] Through the study of clay diatomite of Tengchong Baoshan Expressway in Yunnan Province, considered that it belongs to light and strong expansive extremely soft rock, which has dual physical and hydraulic properties of typical diatomite and expansive clay rock. The former is characterized by high porosity, high water absorption and strong structure; the latter is characterized by high plasticity, remarkable swelling disintegration and swelling disintegration. The appearance is closely related to the content of organic matter. Guo Changbao [2] through the investigation and research on the clay diatomite slope disease of 238 provincial road in Tengchong area, Yunnan Province, considered that it has the characteristics of swelling and strong structure. Under the condition of structural disturbance and water saturation, the mechanical strength is significantly weaken, and the shallow small landslide is easy to occur. The waterproof and drainage design of side slope should be paid attention to, and the construction in rainy season should be avoided.

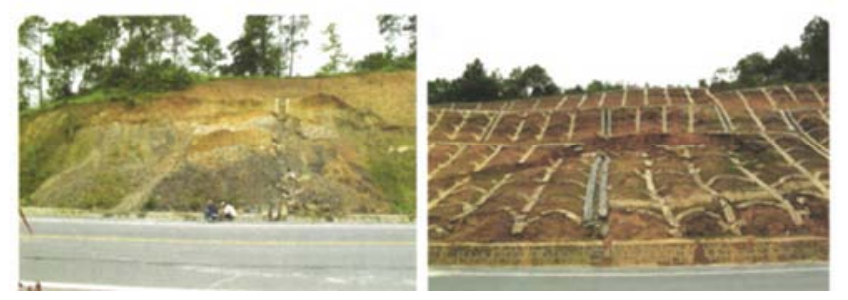

Figure 2. Diatomite landslide in Tengchong, Yunnan.

Through the experimental study of diatomite (soil) in Monterey, Southern California, Day [10] thinks that the diatomite (soil) with low dry weight and high moisture content has low shear strength and high compressibility. Due to the mutual occlusion and rough surface characteristics of diatomite (soil), the performance of diatomite (soil) is the same as that of dense granular material under lower effective stress. However, when the vertical stress is large, the interaction of diatoms is destroyed, which leads to the increase of the compressibility of diatom (soil). The engineering properties of diatoms (soil) become worse immediately and the bearing capacity is lost. The research results of Tateishi [11] on natural diatomite (soil) in Japan show that it has high natural moisture contents, although its strength and elastic modulus are very high.

The newly built high-speed railway passes through the area within Shengzhou and Xinchang of Zhejiang Province in the form of subgrade, tunnel and bridge. It is found that there are a lot of diatomite (soil) in the tertiary multi-stage eruption basalt and multi-stage fluvial lacustrine sedimentary layer of basalt platform. Based on the field test research in Shengzhou, and comparing with the research results of Hong Zhenshun [4], Fang yaoyue [5] and, Gao Huaxi [6], this paper puts forward the research results of diatomite engineering characteristics in this area, and the applicability suggestions of engineering measures for Subgrade Engineering Foundation and slope.

Ma qiuzhu [7] and others have studied the engineering characteristics of diatomite in Namibia. They believe that the serious mismatch between the strength index and compression index of diatomite may lead to great uncertainty in its shear and rheological properties under the action of long-term shear stress, which may lead to large later settlement and deformation.

MaYuan [8] Taking Zhejiang Shengzhou diatomite as the research object, through indoor and outdoor experimental research, proposed that Zhejiang diatomite is generally rich in clay minerals, with the characteristics of extra-large pores, high water content and poor water permeability. And the diatomite's Siliceous shell contains multi-level pores, which is the essential reason for its rich water and higher structural strength than ordinary soil. The key process of engineering property differentiation between white diatomite and blue diatomite is that the white diatomite is buried shallowly and alternately dried and wet. In addition, black diatomite is rich in organic matter, which is the key factor to differentiate its engineering properties and color from white and blue diatomite; the sedimentary environment of diatomite in Zhejiang Province is warm and humid.

The high-speed railway subgrade has very strict requirements on foundation settlement,deformation and safety protection. The post construction settlement of general section shall not exceed $15 \mathrm{~mm}$, and the settlement difference between subgrade and bridge (tunnel) structure joint shall not exceed $5 \mathrm{~mm}$. The slope engineering shall be safe and stable. Therefore, on the premise of lack of engineering experience, it is necessary to conduct field research on Diatomite characteristics and reinforcement measures.

Due to the obvious differences of diatom origin, diatom species, soil structure and chemical composition in different areas, the diatom properties in some areas may not be universal, so this paper can only be used as a reference.

\section{Engineering Characteristics of Diatomite in Shengzhou}

Firstly, a large number of samples were collected in typical construction sites for routine laboratory tests, and the key 
physical and mechanical indexes were analyzed to obtain the basic characteristics of diatomite in Shengzhou, Zhejiang Province, and form the evaluation of the basic characteristics of diatomite in this area.

\subsection{Appearance Characteristics of Diatomite}

From the field drilling situation, the diatomite land is obviously distributed in the base. The surface is thin silty clay; under it is thick white diatomite, its basic bearing capacity is $150-180 \mathrm{kpa}$; under it is blue diatomite and black diatomite which have no fixed sequence, its basic bearing capacity of blue diatomite is $500 \mathrm{kPa}$, its basic bearing capacity of black diatomite is $300 \mathrm{kPa}$; under it is basalt, its basic bearing capacity is $1500 \mathrm{kPa}$.

The appearance characteristics and bearing capacity of different color diatomite samples in Shengzhou are quite different, as shown in Figure 3. The blue diatomite is long columnar, the black is short columnar, and the white is relatively loose and broken.

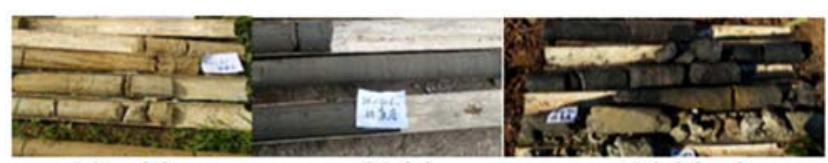
(a) white
(b) blue
(c) black

Figure 3. Diatomite type in Shengzhou region.

\subsection{Microstructure Analysis of Diatomite}

The microstructure of Shengzhou diatomite sample blank was analyzed by electron microscope and microscope in the laboratory, as shown in Figure 4. Seen from Figure 4 (a), the diatomite is mainly composed of intact and broken diatom shell, clay minerals, detrital minerals and organic matter. The diatoms are mainly composed of dinoflagellates and a little of discomorphs, which are cylindrical. The diameter of the shell is $5-30 \mu \mathrm{m}$, and the length is $10-30 \mu \mathrm{m}$.

From the view of single diatom particles in Figure 4 (b), the shell wall of diatom contains multi-stage and large number of ordered microporous structures with pore size less than $0.2 \mu$ $\mathrm{m}$. The shell wall is usually hollow structure, the surface of the shell is uneven, and the diatom particles are interlaced and occluded.

It can be seen from Figure 4 (c) that irregular clay minerals are distributed or filled in the diatom shell wall or diatom interior. The clay minerals in blue diatomite are mainly parallel lamellar and wrinkled lamellar illite or montmorillonite mixed layer minerals, which are arranged in the form of superposition, and mainly in the form of flocculation.

Diatomite has the basic physical properties of low density, high porosity and high water content due to the porous microstructure of diatomite particles.

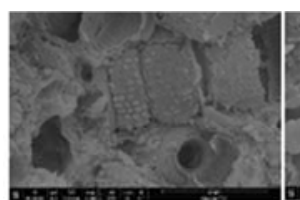

(a) Microstructure

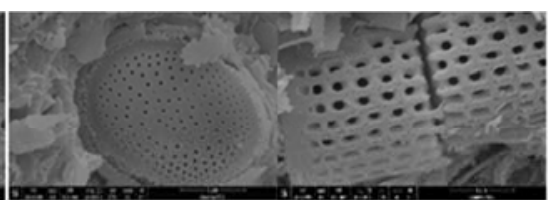

(b) diatom (c) filling minerals
Figure 4. SEM of the blue diatomite $20000 X$

\subsection{Basic Physical Properties of Diatomite}

From the physical and mechanical indexes of field sampling test (see Table 1), the diatomite in Shengzhou area has the characteristics of small dry density, high moisture content, high void ratio, strong structure, easy disintegration, etc., It has the multiple characteristics of clay, soft soil and expansive soil. The physical and mechanical properties of diatomite with different colors have certain differences. Generally, the mechanical properties of blue diatomite are the best, followed by black diatomite and white diatomite, and white diatomite is not suitable to be directly used as the foundation of high-grade railway subgrade engineering. Moreover, the test data show that the in-situ mechanical properties of diatomite (soil) are quite different and uncertain between indoor and outdoor.

The swelling property, water content and plasticity index of diatomite are similar to those of clay, but the range of liquid index of diatomite (soil) is $0.4-0.54$, void ratio is $1.21-1.95$, and the characteristic value of bearing capacity is $150-500 \mathrm{kpa}$. The characteristic value of bearing capacity of cohesive soil with the same liquid index and void ratio is lower than $135 \mathrm{kpa}$. When the SPT blow count is more than 32 , the cohesive soil is generally evaluated as hard, and the liquid index is less than or equal to 0 , while the liquid index of diatomite (soil) is mainly concentrated in the range of $0-0.5$, which is in the hard plastic state.

Table 1. Basic physical-mechanical properties of diatomite.

\begin{tabular}{lllllll}
\hline type & density/(g·cm-3) & Moisture content /\% & Pore ratio & Liquid limit /\% & Plastic limit /\% & Expansion rate /\% \\
\hline white & 1.63 & 55.78 & 1.21 & 62.20 & 33.10 \\
black & 1.64 & 60.69 & 0.78 & 81.10 & 47.20 \\
blue & 1.58 & 61.87 & 1.58 & 74.30 & $1-14$ \\
\hline
\end{tabular}

Table 1. Continued.

\begin{tabular}{lllllll}
\hline type & $\begin{array}{l}\text { Dry saturated water } \\
\text { absorption } / \%\end{array}$ & $\begin{array}{l}\text { Disintegration } \\
\text { resistance index } / \%\end{array}$ & $\begin{array}{l}\text { compressive } \\
\text { strength /MPa }\end{array}$ & Cohesionc/kPa & $\begin{array}{l}\text { Friction angle /( }) \\
\text { ( })\end{array}$ & $\begin{array}{l}\text { Compression } \\
\text { modulus } / \mathbf{M P a}\end{array}$ \\
\hline white & 48.8 & 11.92 & 0.18 & 54.06 & 12.69 \\
black & 81.2 & 6.68 & 0.77 & 56.44 & 27.15 \\
blue & 81.1 & 6.61 & 1.29 & 73.16 & 11.89 \\
\hline
\end{tabular}


The diatomite with high water content and high void ratio can be compared with soft soil, but the compressibility of diatomite (soil) is concentrated in low to medium compressibility, while soft soil is characterized by high compressibility. Soft soil is mainly in soft plastic and flow plastic state, while diatomite (soil) is mostly in hard plastic and plastic state. The basic bearing capacity of soft soil with water content of $50-60 \%$ is about $60-70 \mathrm{kpa}$, and that of diatomite (soil) with water content of $50-64 \%$ is up to $500 \mathrm{kPa}$. It can be seen that although diatomite (soil) has a high void ratio and water content, it has a better strength index than soft soil with similar physical conditions.

The diatomite is rich in clay minerals, impermeable, high in clay content, and often has expansibility, which can be compared with clay rock. The P-wave velocity of black diatomite (soil) is nearly $2 \mathrm{~km} / \mathrm{s}$, which is equivalent to the strong weathering index of hard rock $(1-2 \mathrm{~km} / \mathrm{s})$, and that of white and blue diatomite (soil) is equivalent to that of soft rock $(0.7-1.5 \mathrm{~km} / \mathrm{s})$. However, the clay rock is usually more homogeneous, and the diatomite (soil) pore is much larger than clay rock, and the upper and lower layers are common. The bearing capacity of diatomite (soil) with different colors is also different.

\subsection{Basic Mechanical Properties of Diatomite}

Further tests and studies show that the mechanical properties of Shengzhou diatomite are obviously affected by its structural characteristics, and its state is closely related to the stress. The undisturbed soil sample for FANG Yao-yue's [5] test is white diatomite, which taken from the exit of a tunnel in this section of railway, and the soil depth is $3.5-4 \mathrm{~m}$ below the surface. Through the contrast test of undisturbed soil and remolded soil, credible results have been obtained.

\subsubsection{Analysis of Compression Test Results}

The compression curves for undisturbed and remolded soils are shown in Figure 5. The deformation of undisturbed soil samples is very small when the consolidation pressure is small, and the compression curve is basically horizontal, which conforms to the trend of compression curve of natural sedimentary structural soil. After the consolidation yield stress is reached, the deformation of the soil sample increases sharply, the compression curve drops sharply, and the compression index $\mathrm{C}_{\mathrm{C}}$ reaches 1.14 , which becomes a high compressible soil. The compression curve is basically a straight line because the cementation strength of the remolded soil sample is close to the original pore. Under the same consolidation pressure, the pore ratio is obviously smaller than that of the original sample, and the compression index $\mathrm{C}_{\mathrm{C}}$ is only 0.42 . It is proved that the undisturbed diatomite has a very strong structure and the compression property is greatly weakened after being disturbed.

Using the Ln (1+e)-Lgp double logarithm solution proposed by Butterfield [9], the consolidation yield pressure $\sigma_{\mathrm{p}}$ of Shengzhou diatomite is $1360 \mathrm{kpa}$. According to the estimation of buried depth of soil sample, the effective stress is $68 \mathrm{kpa}$, and the overconsolidation ratio of diatomite undisturbed sample is 20, which belongs to strong structural soil.

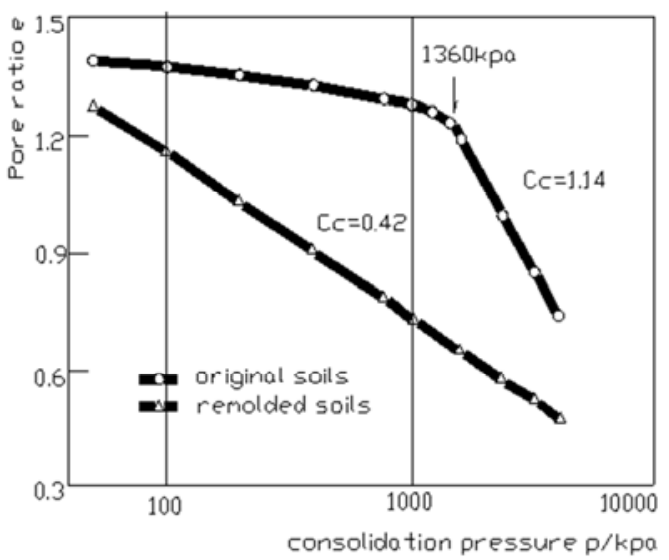

Figure 5. Comparison of compression curves between original and remolded soils.

\subsubsection{Triaxial Undrained Shear Test Results}

The stress-strain curves of undisturbed and remolded samples of diatomite are shown in Figure 6.

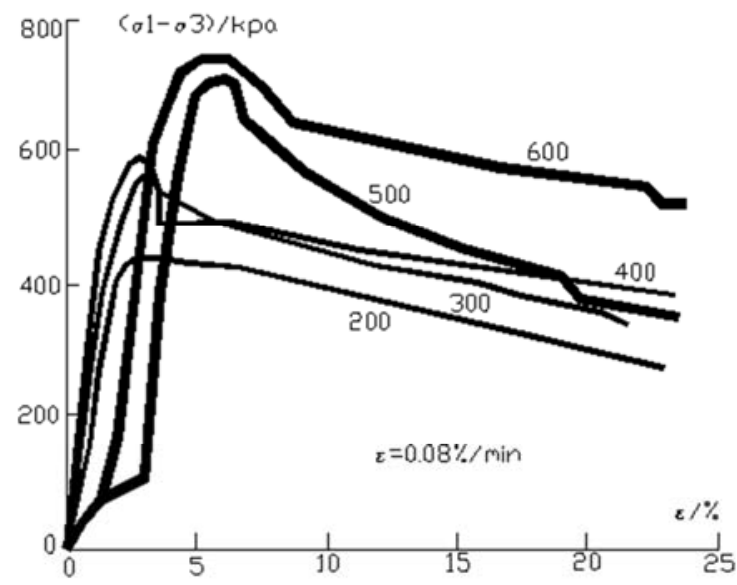

(a) Original soil

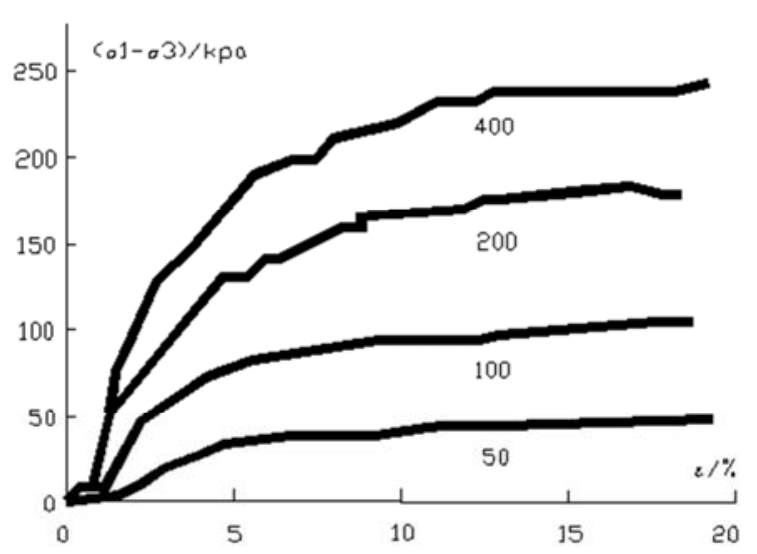

(b) Remolded soil

Figure 6. Triaxial consolidated undrained shear test results of Diatomite. 
It can be seen from Figure 6 (a) that the undisturbed samples show a trend of strain softening under five confining pressures. With the increase of confining pressure, the deviatoric stress of undisturbed samples increases correspondingly, and the initial section of the stress-strain curve is approximately elastic. After reaching the peak value, the structure is destroyed rapidly, and the strain softening suddenly occurs, the softening amplitude increases, and then the deviatoric stress gradually decreases.

It can be seen from Figure 6 (b) that the stress-strain curve of remolded sample is quite different from that of undisturbed sample, and it shows strain hardening state under four kinds of confining pressures. With the increase of confining pressure, the deviatoric stress of remolded sample increases correspondingly. From the value of peak deviatoric stress, under the same confining pressure, the peak deviatoric stress of remolded sample is much smaller than that of undisturbed sample.

\subsubsection{Failure Modes of Diatomite Samples}

The failure modes of undisturbed samples and remolded samples are shown in Figure 7. According to the results of $\mathrm{Cu}$ test, the undisturbed samples (a) are more prone to strain localization, resulting in shear band failure. The cohesion $\mathrm{c}$ is 90.2-150.8kpa, and the internal friction angle is $22.7-26.1^{\circ}$. However, due to the loss of structure, the cementation between particles no longer exists in remolded soil (b), which is dominated by uniform deformation and failure of dispersive cracks, resulting in bulging deformation. Its cohesion $\mathrm{c}$ is $14.1-22.5 \mathrm{kpa}$, and internal friction angle is $13.4-18.6^{\circ}$. It shows that the structural strength of diatomite has an effect on the failure mode of soil samples. The existence of structure makes the cohesion of undisturbed soil much higher than that of ordinary soil, and the structural failure obviously changes the cohesion and internal friction angle of soil.

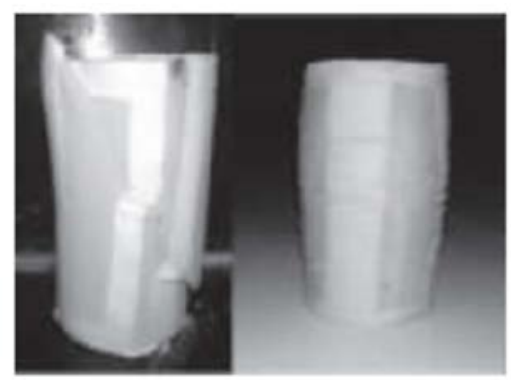

(a) Original soil (b)Remolded soil

Figure 7. Failure modes of diatomite samples.

\subsubsection{Permeability of Diatomite Samples}

The permeability of diatomite samples in the laboratory is very strong, which is consistent with the characteristics of macropore ratio, but it is different with the later field test results. Further analysis shows that, due to the characteristics of macropore ratio, the permeability coefficient of small soil samples and diatomite soil layer with a certain thickness is larger. However, due to the characteristics of pore sealing, the permeability effect is limited to a certain thickness range, when it exceeds this value with the increase of thickness, the influence of permeability decreases sharply.

\section{Field Engineering Test of Diatomite in Shengzhou}

High speed railway subgrade has high requirements for long-term settlement and deformation of foundation. Based on the engineering characteristics of diatom soil foundation in this area, and the small compression modulus and large deformation of white diatom soil layer in the upper layer of foundation, which can not be directly used as the requirement of bearing foundation, experiments on site were carried for providing reasonable and reliable engineering measures. such as the selection of diatom soil foundation reinforcement pile type, bearing capacity of composite foundation, dynamic characteristics of cutting bed structure, the influence depth of rainfall and protection test of cutting slope.

\subsection{Test of Pile Type Selection for Foundation Reinforcement}

In view of the fact that the bearing capacity of white diatomite on the surface of subgrade is $150-180 \mathrm{kpa}$, and the void ratio and compression modulus are small, the pile type comparison tests of diatomite soil foundation reinforced by screw pile, CFG pile, plain concrete pile, high-pressure jet grouting pile and reinforced concrete cast-in-place pile are carried out on site. Through the field construction technology, pile integrity quality inspection, single pile static load and dynamic excitation test, the comparison is made, The reinforcement effect and rationality of different diatom soil pile types are analyzed.

A continuous section (the distribution of foundation soil layer is shown in Figure 8 is selected to test the screw pile (L), plain concrete pile (S) and CFG pile (C). The pile length is $15-20 \mathrm{~m}$, and the bottom of the pile enters into the blue diatom soil layer. In addition, two nearby points are selected to test the jet grouting pile and cast-in-place concrete pile. The cast-in-place pile is also used as the actual engineering pile, so it is only loaded to the design load. The test results of different pile types are summarized in Table 2 .

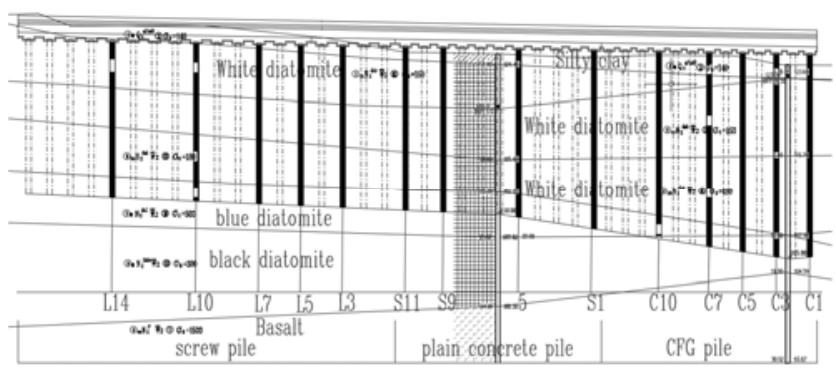

Figure 8. Study on the stratum of pile type test site for foundation reinforcement.

\subsubsection{Pile Quality}

From the perspective of pile quality integrity, CFG pile, screw pile, plain concrete pile and reinforced concrete pile are 
inspected by low strain method, and the overall pile quality meets the requirements. The latter two pile types are relatively good, and the shallow slight defects are mainly caused by the disturbance of soil between piles. The high pressure jet grouting pile is inspected by coring method. The results show that the cement slurry within the rangr of pile center $25 \mathrm{~cm}$ is full and the pile forming effect is good. The cement slurry outside the pile radius of $25 \mathrm{~cm}$ decreases gradually, and the cement slurry within the range of $0.5 \mathrm{~m}$ at the bottom of the pile is less. It shows that the strong structure of diatomite and closed pores can prevent the entry of high-pressure cement slurry, and there is uneven reinforcement phenomenon. It has certain engineering risks in the application of diatomite foundation treatment.

\subsubsection{Bearing Capacity of Single Pile}

From the bearing capacity of single pile, the standard values of ultimate bearing capacity of CFG pile, screw pile, plain concrete pile and reinforced concrete pile are $1095 \mathrm{kn}, 412 \mathrm{kn}$, $980 \mathrm{kn}$ and $2860 \mathrm{kn}$ respectively. The bearing capacity of screw pile can not meet the design requirements. The main reason is that the rotation and compaction effect of the screw pile during the construction destroys the diatomite structure in a certain range around the pile and reduces the shear strength. The release of the free water in the closed pores softens the diatomite saturated at the pile-soil interface and reduces the bond strength, which caused the soil around the pile can not support the bearing performance of the screw pile. The above single pile bearing capacity of CFG pile, screw pile and plain concrete pile are the minimum values under normal, normal (excitation), immersion and immersion (excitation) conditions, which generally show a downward trend. However, due to the influence depth of immersion between $0.5-2.5 \mathrm{~m}$, the actual decline is not large.

The so-called excitation is to consider the dynamic characteristics of single pile by simulating the long-term dynamic load condition of train, the static stress at the top of pile is controlled to be $120 \mathrm{kPa}$, the peak dynamic stress is $8-12 \mathrm{kpa}$, and the excitation frequency is $12 \mathrm{~Hz}$. The natural state and water immersion condition of screw pile, CFG pile and plain concrete pile are respectively loaded with fatigue for no more than 2 millions cycles. It can be seen from the above table that the dynamic performance and fatigue characteristics of plain concrete pile are obviously better than those of CFG pile and screw pile.

\subsubsection{Construction and Cost}

From the perspective of site construction, screw pile is constructed by screw soil squeezing technology, with small spacing, so mud drilling occurs repeatedly. And it is difficult to rotate when met the silica gel soil foundation which mixed with basalt lens or large boulder, the hole introduction will cause the construction cycle and unit price increase; the plain concrete pile and reinforced concrete cast-in-place pile are constructed by rotary drilling, which is basically not impossible Due to the stratum limitation. From the unit price of comprehensive square meter of foundation treatment, $\mathrm{CFG}$ pile $<$ plain concrete pile $<$ reinforced concrete pouring pile.

Table 2. Achievement table of pile type for diatom soil foundation reinforcement in Shengzhou.

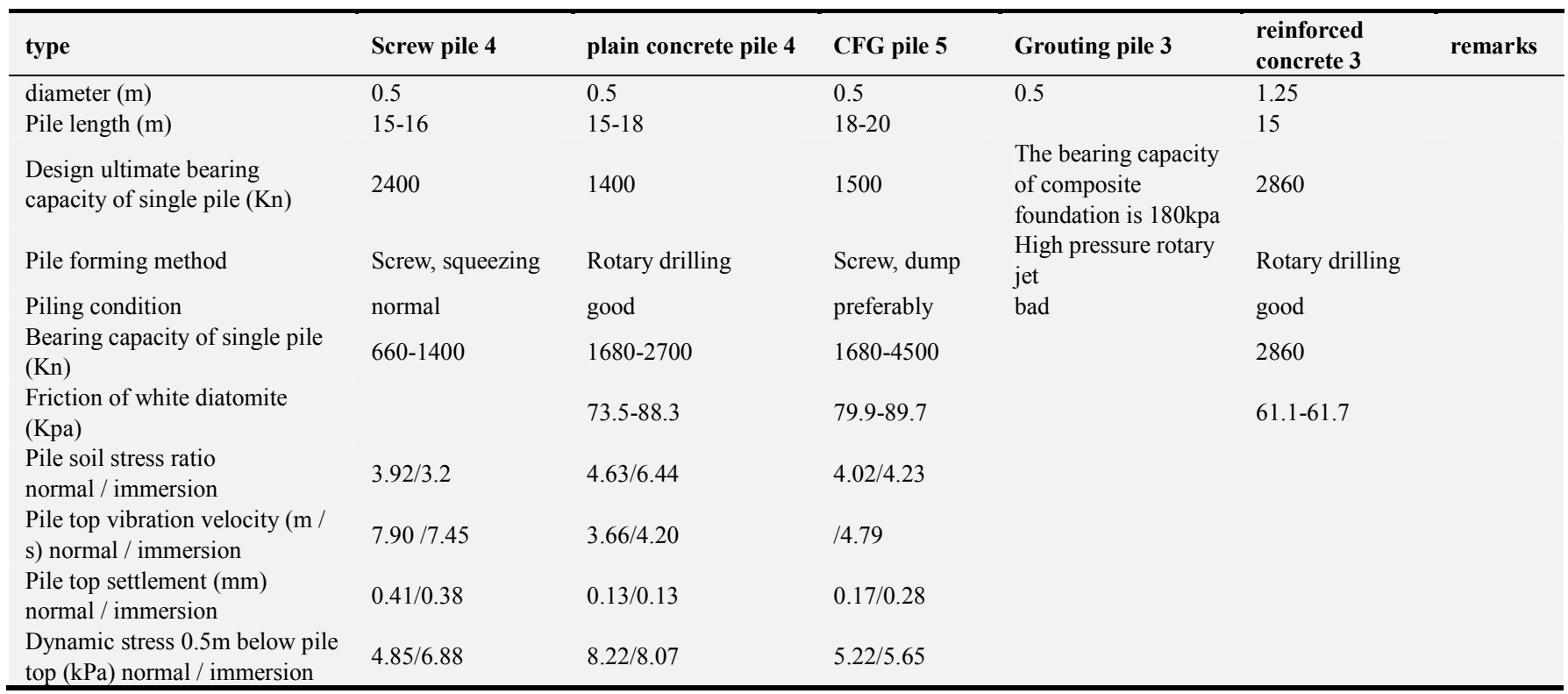

\subsection{Experimental Study on Bearing Capacity of Composite Foundation}

acording to the preliminary selection of pile type and layout type of pile raft composite foundation in the design, CFG pile and plain concrete pile raft test sections (as shown in Figure 9) are set on site respectively. Through pre arranging monitoring components (as shown in FIGURE 10), raft, soil stress between piles, settlement and lateral displacement are monitored on site during construction and dynamic performance test period of subgrade structure, and their applicability is analyzed and studied. 


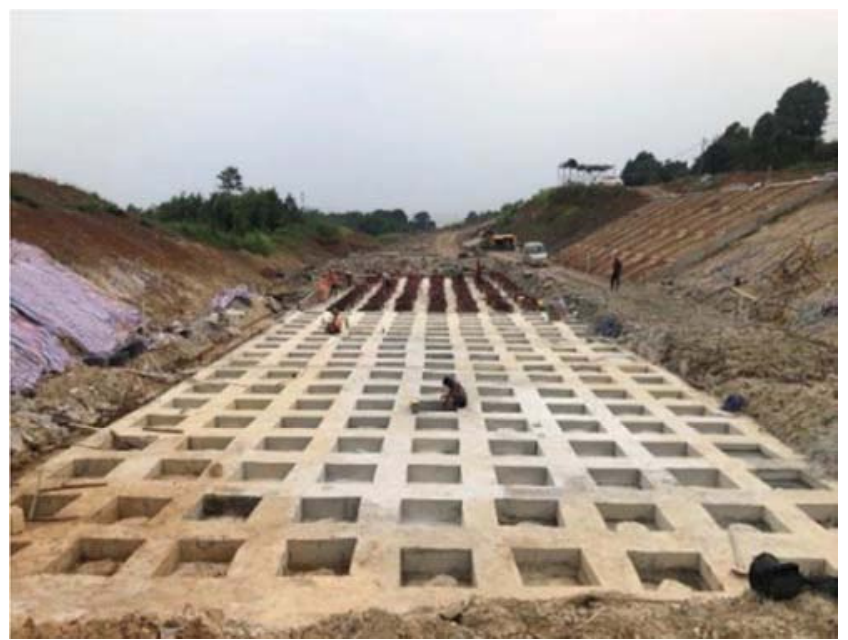

Figure 9. Plane position relation of pile raft structure.

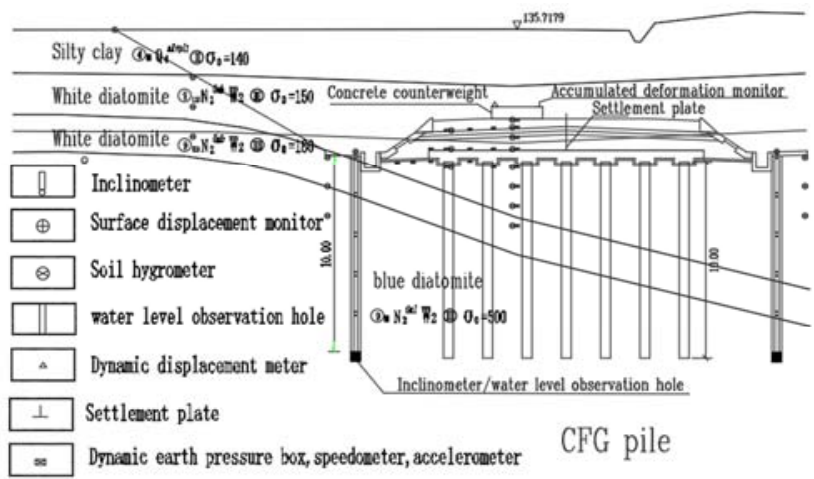

Figure 10. Composite foundation section sensor layout.

CFG pile diameter is $0.5 \mathrm{~m}$. Pile spacing is $1.6 \mathrm{~m}$. Concrete pile diameter is $0.55 \mathrm{~m}$. Pile spacing is $1.8 \mathrm{~m}$. Square layout, pile length is $20 \mathrm{~m} .1 .0 \mathrm{~m} \times 1.0 \mathrm{~m} \mathrm{C} 30$ cap is set on the top of pile. The thickness of upper raft is $0.4 \mathrm{~m}$. The height of subgrade above raft is $1.6 \mathrm{~m}$. The actual height above original soil layer is $2.3 \mathrm{~m}$ including raft and its underlying cushion.

\subsubsection{Settlement and Deformation of Raft}

The settlement after the completion of raft pouring is shown in Figure 11. In the initial stage of upper filling, the settlement of raft fluctuates relatively large due to the influence of construction machinery and operation equipment on the subgrade bed and later vibration exciter, but the actual variation is small. When the subgrade filling is completed, the average settlement of CFG section raft is $3.64 \mathrm{~mm}$, and that of plain concrete pile raft is $2.94 \mathrm{~mm}$, which indicates that the overall settlement and stability of plain concrete pile raft composite foundation is better than that of CFG pile raft composite foundation.

The central internal force of raft increases with the increase of subgrade filling height. After filling, it increases slowly and tends to be stable. The transverse stress of the upper part of the raft is negative, and the transverse stress of the lower part is positive, and the stress of the center of the raft is greater than that of the two sides. The maximum tensile stress of raft is $1.1 \mathrm{MPa}$, which is less than the tensile strength of $\mathrm{C} 40$ concrete.

Further analysis shows that the pile cap on the top of the pile overlaps with the raft, which does not form consolidation, and the thickness of the raft is small, resulting in the larger vertical amplitude under the external dynamic load.

\subsubsection{Single Point Settlement of Soil Between Piles}

The single point settlement meter of CFG pile raft section is respectively buried at the depth of $2.3 \mathrm{~m}, 5.1 \mathrm{~m}, 11.8 \mathrm{~m}, 20 \mathrm{~m}$ and $32 \mathrm{~m} . \mathrm{d} 2-20$ is the junction between the reinforcement area and the underlying layer. The change of settlement meter is shown in Figure 12. After the raft is hardened, the load above the raft is more distributed to the piles, the soil between the piles is less stressed, rebound deformation occurs, and then the settlement gradually decreases and tends to be stable. When the subgrade filling is completed, the maximum values of $\mathrm{d} 2-20$ and $\mathrm{d} 2-32$ are $3.18 \mathrm{~mm}$ and $3.26 \mathrm{~mm}$ respectively. It can be seen that the subgrade compression mainly occurs in the pile-soil reinforcement area, the value is $3.18 \mathrm{~mm}$, and the compression of the underlying layer is $0.08 \mathrm{~mm}$, accounting for $2.45 \%$ of the total compression. In the later stage of $\mathrm{d} 2-32$, the difference of foundation soil compression before and after excitation is $0.28 \mathrm{~mm}$.

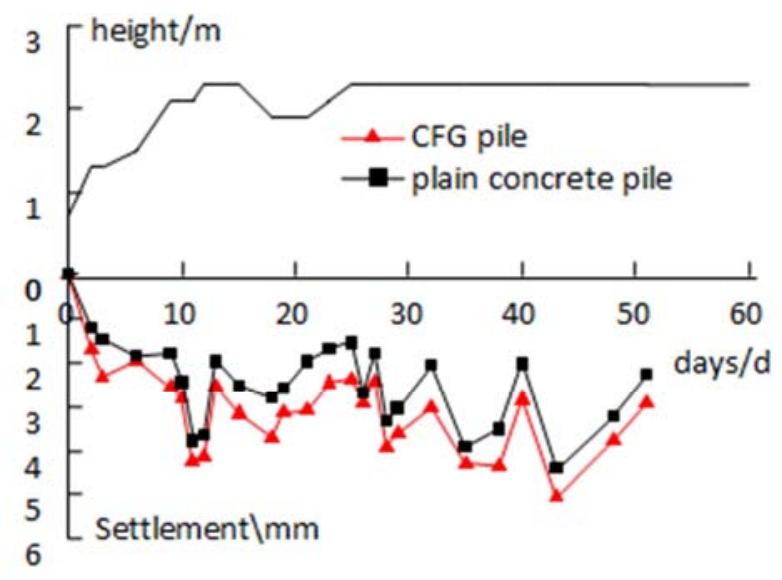

Figure 11. Settlement deformation of the raft.

The single point settlement meter of plain concrete pile raft section is respectively buried at the depth of $2.3 \mathrm{~m}, 7.7 \mathrm{~m}$, $11.8 \mathrm{~m}$ and $32 \mathrm{~m} . \mathrm{d} 3-20$ is the junction between the reinforcement area and the underlying layer. The change of settlement meter is shown in Figure 13. The compression of foundation soil increases with the increase of filling height, increases sharply at the beginning of filling, then increases slowly, and finally tends to be stable. When the subgrade filling is completed, the maximum values of $\mathrm{d} 3-2.3, \mathrm{~d} 3-7.7$, $\mathrm{d} 3-20$ and $\mathrm{d} 3-32$ are $1.5,1.76,1.78$ and $1.87 \mathrm{~mm}$ respectively. In the later stage, the difference of compression of $\mathrm{d} 3-32$ foundation soil before and after excitation is $0.06 \mathrm{~mm}$, which is less than that of CFG section at the same depth.

\subsubsection{Pile Soil Stress Ratio}

The change of pile-soil stress ratio is shown in Figure 14. At the initial stage of embankment filling above raft, there is consolidation settlement of soil between piles, and the 
settlement of soil between piles is greater than that of piles. At this time, raft mainly transfers load to piles, and pile-soil stress is relatively large. With the increase of embankment filling height, the upper load increases, and pile settlement increases. Raft gradually shares part of load to soil between piles, and pile-soil stress is readjusted The soil stress ratio decreases. After a period of embankment filling, the pile-soil stress ratio of CFG section is 15.21, and that of plain concrete pile section is 39.8 , which indicates that the integrity of plain concrete pile raft structure is better.

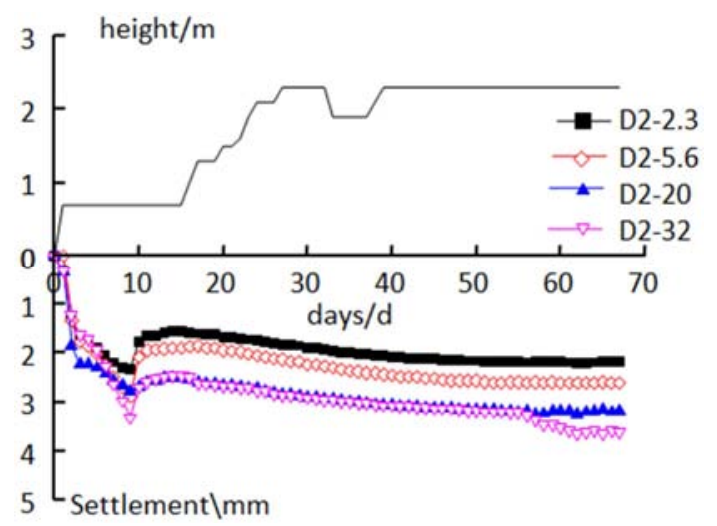

Figure 12. CFG composite foundation settlement of single-point subsidence gage.

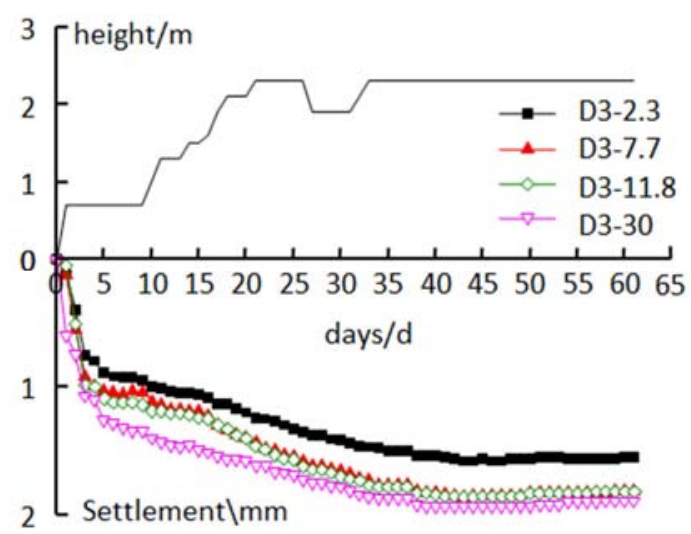

Figure 13. Plain concrete pile composite foundation settlement of single-point subsidence gage.

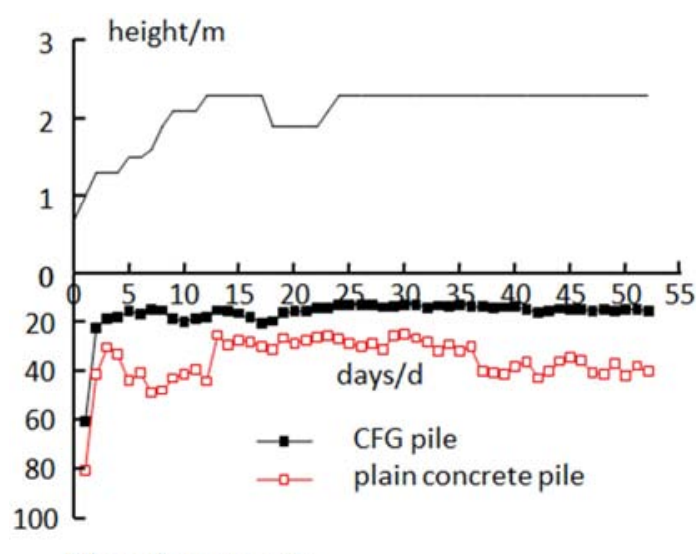

Pile soil stress ratio

Figure 14. The variation of pile-soil stress ratio.

\subsubsection{Dynamic Excitation}

After the completion of subgrade filling, the bearing capacity of pile raft composite foundation under repeated excitation load is tested in the process of dynamic characteristics test of subgrade structure. The results show that the acceleration of raft in the center of the line is less than $0.8 \mathrm{~m} / \mathrm{s} 2$, and the acceleration of raft increases about $15 \%$ before and after the subgrade is soaked. The speed of raft near the center of the line is less than $1.3 \mathrm{~m} / \mathrm{s}$, and the speed increases by about $13 \%$ before and after the foundation bed is soaked. the acceleration of soil between piles at $0.5 \mathrm{~m}$ below the raft on the center line of the line is $0.63-0.71 \mathrm{~m} / \mathrm{s}$ ?, the speed is $2.03-2.84 \mathrm{~m} / \mathrm{s}$, and the dynamic stress is $0.63-0.74 \mathrm{kpa}$, which are all small, and the degradation rate is about $80 \%$ at $3 \mathrm{M}$ down. The dynamic stress at the top of the pile on the center line of the line is $5.6-6.6 \mathrm{kPa}$, and the attenuation in the middle of the pile is about $70 \%$. The pile tip can be attenuated by about $80 \%$, and the value has no obvious change before and after the foundation bed is soaked. Because the raft and the concrete isolation layer on both sides of the raft block the infiltration of water in the upper part of the foundation bed, the water content of the foundation soil under the raft has no effect. In general, plain concrete pile raft composite foundation is slightly better than CFG pile.

\subsection{Test on Dynamic Characteristics of Cutting Subgrade Structure}

According to the structure of subgrade bed preliminarily selected in the design (see Figure 15), the dynamic load is applied on the subgrade surface to simulate the dynamic action of train (see Figure 16), and the dynamic response and drainage effect of subgrade bed are monitored by pre embedded components. During the test, the measured maximum dynamic stress on the surface of the subgrade bed is $49 \mathrm{kPa}$, the loading frequency is $14 \mathrm{~Hz}$, and the loading times are not more than 2 million under normal condition and soaking condition respectively until it is stable.

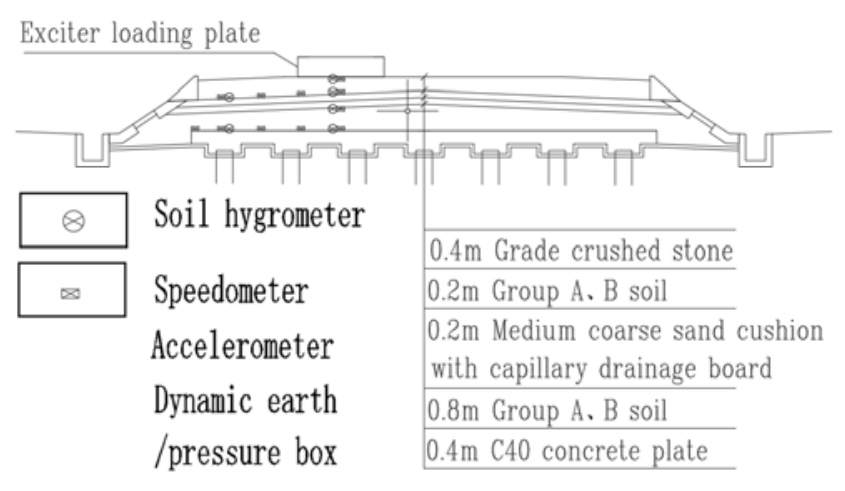

Figure 15. Waterproof and drainage subgrade bed.

There is no waterproof and drainage structure layer in the traditional subgrade structure. In the test section, a layer of 0.2 $\mathrm{m}$ thick is set $0.6 \mathrm{~m}$ below the top surface of the cutting subgrade bed The capillary waterproof board is a composite structure of smooth surface and capillary surface, in which the smooth surface is used for water separation and the capillary 
surface is used for drainage. The composite structure combined with the medium coarse sand cushion to form an anti drainage layer can quickly discharge the seepage water and prevent it from seeping into the bottom layer of the subgrade bed and diatom soil foundation.

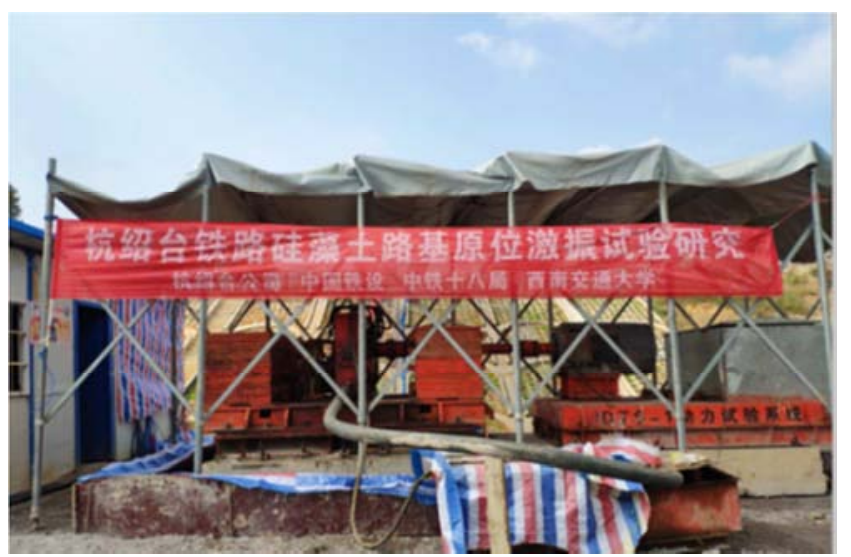

Figure 16. Field dynamic experimental study.

\subsubsection{Dynamic Response}

See Table 3 and Figure 17 for the variation of dynamic stress, acceleration and velocity along the depth direction after the dynamic response of subgrade structure is stable. Compared with the normal state, the dynamic response values at the center of the line increase slightly in the water immersion state. In the water immersion state, the dynamic response of the designed subgrade structure is the same as that of the traditional subgrade structure, the upper part of the waterproof and drainage layer is the same, and the rebound of the material at the top of the waterproof and drainage layer increases slightly, while the lower part decreases obviously. It shows that the existence of waterproof and drainage layer can obviously reduce the transmission of dynamic stress, acceleration and velocity in the subgrade structure.

Through the settlement comparative analysis, it can be seen that during the excitation test, the settlement of the loading plate is $20 \mathrm{~mm} \sim 35 \mathrm{~mm}$ after the traditional foundation is soaked in water. While the settlement of the loading plate is $15.44 \mathrm{~mm} \sim 23.41 \mathrm{~mm}$ after the capillary waterproof and drainage structure layer is laid, which indicates that the influence of dynamic load and dynamic water under the surface layer of the foundation is obviously weakened after the capillary waterproof and drainage structure layer is laid.

Table 3. Stable value of dynamic stress at different depth of subgrade structure.

\begin{tabular}{lllllll}
\hline \multirow{2}{*}{ Depth (m) } & \multicolumn{2}{l}{ Dynamic stress $(\mathbf{k P a})$} & & & \\
\cline { 2 - 7 } & \multicolumn{2}{l}{ Traditional foundation bed structure } & \multicolumn{2}{l}{ Design of subgrade bed structure } & & Immersion \\
\hline status & normal & Immersion & normal & Immersion & normal & \\
\hline 0 & 46.03 & 46.5 & 38.02 & 47.75 & 38.61 & 47.50 \\
0.4 & 35.65 & 33.48 & 22.04 & 27.52 & 33.53 & 37.81 \\
0.8 & $/$ & 25.58 & 17.47 & 21.61 & 21.34 & 26.84 \\
1.6 & 15.21 & 14.88 & 14.45 & 16.22 & 13.17 & 17.35 \\
\hline
\end{tabular}

\subsubsection{Waterproof and Drainage Effect}

See Table 4 for the change rule of hygrometer before and after soaking at different positions of the subgrade surface.

The hygrometer readings at $0,0.4 \mathrm{~m}$ and $0.8 \mathrm{~m}$ below the traditional subgrade surface have obvious changes after soaking. Affected by the rainstorm during the filling period, the hygrometer at $1.6 \mathrm{~m}$ below the subgrade surface basically has no change before and after soaking. Due to the influence of capillary drainage board on waterproof and drainage subgrade bed, due to the high water content of stagnant water at $0 \mathrm{~m}$ of subgrade surface, the drainage at $0.4 \mathrm{~m}$ is unobstructed, and the data at $0.8 \mathrm{~m}$ is basically unchanged. The hygrometer at $1.6 \mathrm{~m}$ has no change before and after immersion. It can be seen that the humidity of the subgrade filling above the capillary waterproof and drainage board structure layer of the waterproof and drainage subgrade increases rapidly after immersion. While the humidity of the subgrade filling below the capillary waterproof and drainage layer does not change significantly after immersion, which indicates that the capillary waterproof and drainage layer has good waterproof and drainage effect during the immersion vibration test.
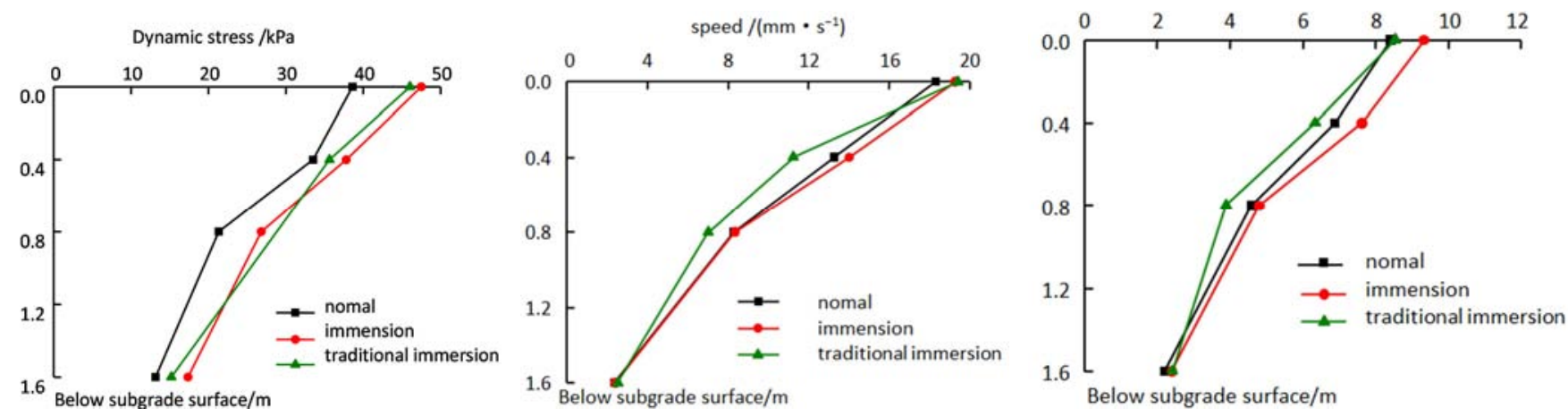

Figure 17. Dynamic response along the direction of depth. 
Table 4. Water content change of subgrade bed.

\begin{tabular}{|c|c|c|c|c|c|c|}
\hline \multirow{2}{*}{ type } & \multirow{2}{*}{ status } & \multicolumn{5}{|c|}{ Water content (below the surface of subgrade)/\% } \\
\hline & & $0.0 \mathrm{~m}$ & $0.4 \mathrm{~m}$ & $0.8 \mathrm{~m}$ & $1.6 \mathrm{~m}$ & \\
\hline \multirow{2}{*}{ traditional subgrade } & normal & 22.240 & 33.360 & 37.010 & 69.370 & 60.500 \\
\hline & Immersion & 58.880 & 50.460 & 66.650 & 69.720 & 60.300 \\
\hline \multirow{2}{*}{ waterproof and drainage subgrade } & normal & 6.955 & 52.885 & 41.175 & 55.552 & 55.266 \\
\hline & Immersion & 76.818 & 51.749 & 40.841 & 54.275 & 54.886 \\
\hline
\end{tabular}

\subsection{Rainfall and Protection Engineering Test of Cutting Slope}

The field investigation shows that the exposed diatomite slope has reticular cracks, the slope toe has peeled off, and the soil has umbrella shaped deposition. In order to ensure the stability of the excavated artificial slope, the field tests of rainfall and slope protection effect were carried out.

\subsubsection{General Situation of Rainfall Test On Cutting Slope}

In order to study the deformation characteristics of diatomite cutting slope under the condition of rainfall and the characteristics of crack development under the action of dry wet cycle, two artificial slopes were selected for rainfall test (see Figure 18), and the slope ratios were 1:1.5 and 1:2.0 respectively. The stratum in this section is covered with silty clay with a thickness of less than $3 \mathrm{~m}$ and the underlying white and blue diatomite (soil) is with a thickness of $25-40 \mathrm{~m}$. The layout of embedded monitoring components is shown in Figure 19, and the artificial rainfall equipment is set, which can simulate the maximum monthly rainfall of 347.0-715.4 $\mathrm{mm}$ in this area in recent 50 years. The test period was rainy season, and natural rainfall and rainstorm during typhoon also provided convenient conditions for the test.

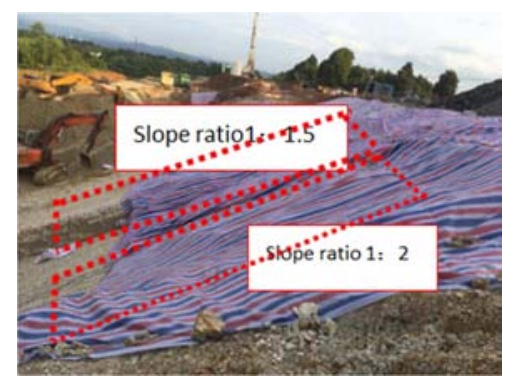

Figure 18. Field test of diatomite slope rainfall.

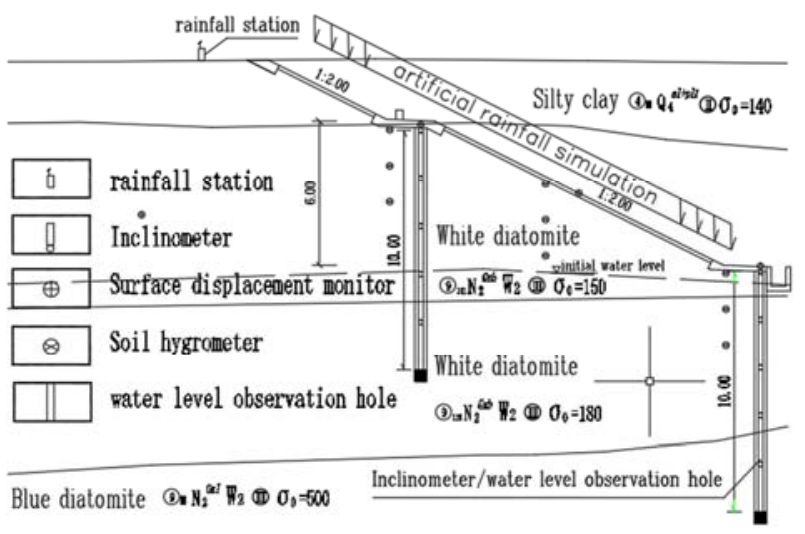

Figure 19. The sensor location (unit: $m$ ).
The infiltration law of $\mathrm{R} 2$ section with slope ratio of 1:2.0 is shown in Figure 20. Under the condition of rainfall, the water content of soil layer at different depths increases sharply until it is saturated. After that, for a long time, the water content at $0.2 \mathrm{~m}$ is greatly affected by the external climate environment, while the water content at $0.5 \mathrm{~m}$ and $1.5 \mathrm{~m}$ is basically saturated, which is less affected by the external climate environment.

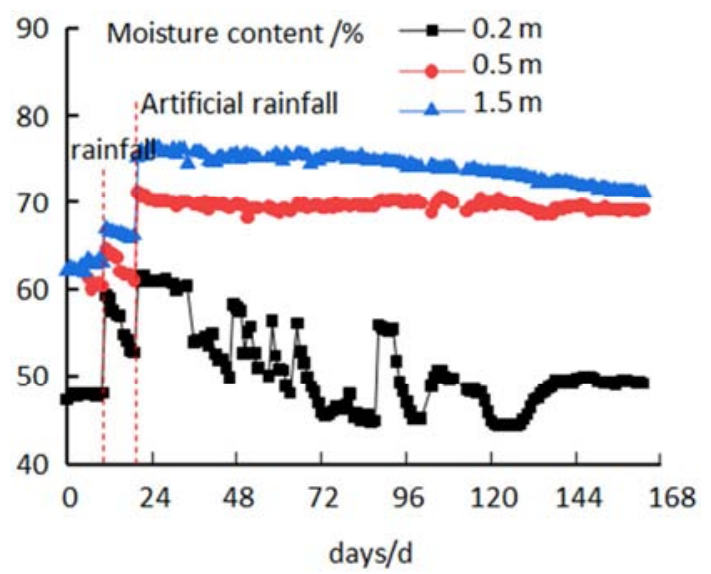

Figure 20. Characteristics of slope infiltration under rainfall.

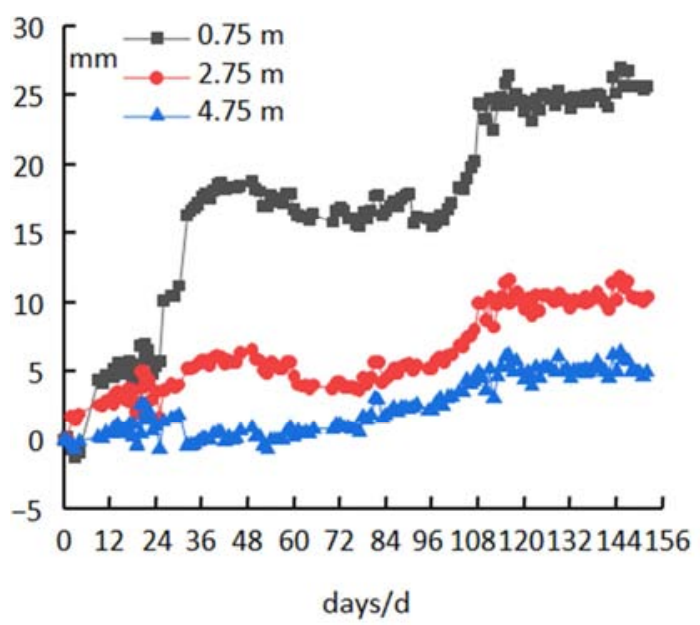

Figure 21. Horizontal deformation of 1;2.0 slope.

The change rule of slope slope rate ays1:2.0 is shown in Figure 21. The increase is small during rainfall, and there is a large increase after rainfall, with obvious lag effect. The horizontal displacement at $0.75 \mathrm{~m}, 2.75$ and 4.75 from the slope top surface is $25.7 \mathrm{~mm}, 10.8 \mathrm{~mm}$ and $6.4 \mathrm{~mm}$ respectively. 1: 1.5 the horizontal displacement of the slope from the top surface of the slope is $0.75 \mathrm{~m}, 2.75 \mathrm{~m}, 4.75 \mathrm{~m}, 6.75 \mathrm{~m}$ and $8.75 \mathrm{~m}$, respectively, $51.3 \mathrm{~mm}, 11.2 \mathrm{~mm}, 10.5 \mathrm{~mm}, 7.4 \mathrm{~mm}$ and $2.4 \mathrm{~mm}$. The displacement of slope mainly occurs between 0.75 and 
2.75 from the surface, which is shallow surface sliding. The horizontal displacement at the toe of the slope is less affected by rainfall, and the displacement of each soil layer at the toe of the slope is less different.

The variation of crack width and depth with time in the process of crack development of diatomite under the action of dry wet cycle is shown in Figure 22. After the artificial slope is excavated and formed, diatomite with high moisture content is exposed to the natural environment, and the water in the shallow layer evaporates rapidly under the action of sunlight and high temperature. Because the pores of deep soil are closed, the water evaporation is slow, and the water content difference between the upper and lower parts is significant, resulting in the initial cracks. With the passage of time, the soil on the surface of the slope continues to crack, and the cracks gradually develop to the depth, leading to the disintegration of the soil on the surface of the slope. The width of the natural slope cracks can reach $10-25 \mathrm{~mm}$, and the depth can reach $40-60 \mathrm{~cm}$ in 4 months.

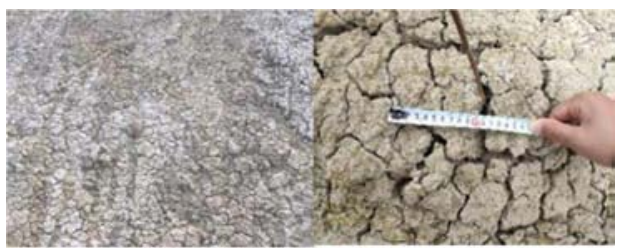

(a) 30 days

(b) 169 days

Figure 22. Fracture development of natural slope.

\subsubsection{Slope Protection Engineering Test}

For the artificial slope of diatomite cutting, the slope ratio is initially determined to be 1:2.0, and two types of slope protection are adopted, i.e. arch skeleton and anchor lattice beam.

During the pull-out strength test of anchor, it is found that the pull-out strength of No. 2 and No. 3 anchor entering diatom soil layer is $36.74 \mathrm{kn}$ and $35.54 \mathrm{kn}$ respectively, which does not meet the requirement of $90 \mathrm{kN}$ design value of anchor. The reason is that the borehole disturbance destroys the closed pores of diatomite, and the free water releases to soften the soil layer, resulting in the decrease of its mechanical properties, and the soil layer can not provide enough bond strength for the anchor.

The arch skeleton slope with the thickness of $0.8 \mathrm{~m}$ is adopted, and $0.4 \mathrm{~m}$ planting soil is laid inside the skeleton to seal diatomite. The test shows that the slope is basically stable under rainstorm conditions, and the displacement of the top of the slope is only $3.7 \mathrm{~mm}$, so the protection effect is good.

\section{Engineering Measures}

According to the results of field test and research, the following suggestions are put forward for the design engineering measures of the diatom soil section of Shengzhou railway

(1) The diatom soil foundation of embankment can adopt plain concrete or $\mathrm{CFG}$ pile raft foundation to control settlement and deformation.
(2) For diatomite cutting, drainage and water isolation measures shall be taken for subgrade structure, and cast-in-place pile slab or plain concrete pile raft foundation can be used for foundation below subgrade

(3) The ratio of diatomite cutting slope can be 1:2.0, the slope should be protected by skeleton slope protection, the thickness of skeleton should not be less than $0.6 \mathrm{~m}$, and planting soil with thickness of not less than $0.3 \mathrm{~m}$ should be laid in the skeleton.

At present, the railway subgrade project in diatomite area has been completed and track laying starts. According to the observation data, the settlement deformation is very small and tends to be stable. In recent on-site inspection after rain, it was found that there was water seepage at some slope points at the junction of silty clay and diatom soil layer, and the slope was basically stable. The line will be put into operation by the end of 2021, and tracking monitoring and analysis will be carried out all the time to enrich and improve the experience of diatomite engineering characteristics and rationality of engineering measures.

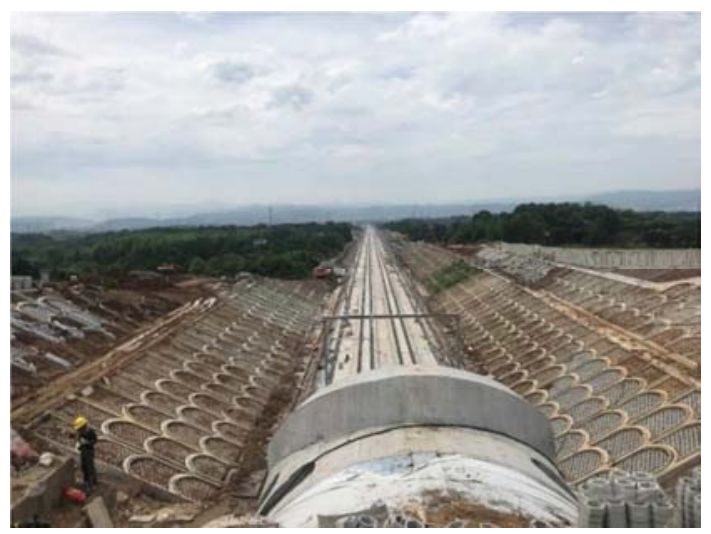

Figure 23. track have been lay on diatomite subgrade.

\section{Conclusion}

Based on the new railway project, this paper carried out the field comprehensive test research of diatomite subgrade project in Shengzhou, Zhejiang Province. The following conclusions are drawn for the test section.

(1) Diatomite soil has low natural density, large void ratio, high water content, sensitive to natural environment and climate, dry shrinkage and wet expansion, and relative deformation and strength, so it is not suitable to be directly used as high-grade railway foundation.

(2) In diatomite soil foundation treatment, the squeezing effect of screw pile is obvious, the mud bag sticking phenomenon is easy to appear in construction. The bond strength of diatomite is obviously reduced, the bearing capacity of screw pile is difficult to play, so it is not suitable for diatomite soil foundation reinforcement; the strength distribution of pile body is uneven, the pile forming effect is poor, and the reinforcement effect is not good when high pressure jet grouting pile is used. CFG pile, plain concrete pile and reinforced concrete 
pile are suitable for diatomite soil foundation reinforcement Diatom soil foundation reinforcement.

(3) The results show that the pile-soil stress ratio of CFG is 15.21 , and the average settlement of raft center is 3.64 $\mathrm{mm}$. The pile-soil stress ratio of plain concrete is 39.8 , and the average settlement of raft center is $2.94 \mathrm{~mm}$. Pile raft foundation structure has good settlement control effect, which can meet the requirements of deformation control for subgrade. In contrast, the effect of plain concrete pile is better.

(4) It has good effect to set capillary waterproof and drainage board in diatomite cutting bed structure. The anti-drainage layer can significantly reduce the transmission of dynamic stress, acceleration and velocity in the subgrade structure.

(5) Diatomite cutting artificial slope is easy to form network cracks with depth of 40-60 $\mathrm{cm}$ under the action of drying and wetting cycle, which can induce shallow landslide. Adopting 1:2.0 slope ratio, arched skeleton with thickness of no less than $0.8 \mathrm{~m}$ and planting grass with foreign soil has good protection and reinforcement effect on Diatomite slope.

\section{References}

[1] ZHANG Yong-shuang, GUO Chang-bao, QU Yong-xin, et al. Discovery of swelling diatomite at Tengchong, Yunnan Province and its implication in engineering geology $[\mathrm{J}]$. Journal of Engineering Geology, 2012, 20 (2): 266-275.

[2] GUO Chang-bao, ZHOU Neng-juan, FU Xiao-xiao, et al. The optimization design of the research on the formation mechanism, prevention and control of landslide along clayey diatomite highway in Tengchong, Yunnan Province [J]. Geological Bulletin of China, 2013, 32 (12): 2021-2030.
[3] ZHANG Yong-shuang, GUO Chang-bao, QU Yong-xin, et al. Research on mechanical properties of swelling diatomite and their geohazard effects [J]. Rock and Soil Mechanics, 2013, 34 (1): 23-30.

[4] HONG Zhen-shun, TATEISHI Yoshitak, DENG Yong- feng. Relationship between entrance pore distribution and stress level of natural sedimentary diatomaceous soil $[\mathrm{J}]$. Rock and Soil Mechanics, 2004, 25 (7): 1023-1026.

[5] FANG Yao-yue, JIANG Jun, JIANG Huang-hui. Research on the microstructure and the mechanical properties of shengzhou diatomite [J]. Low Temperature Architecture Technology, 2019, 41 (2): 75-77, 81.

[6] GAO Hua-xi, YIN Kun-long, ZHOU Chun-mei. Diatomite landslides stability analysis and timeforecast [J]. Journal of Northwest University (NaturalScience Edition), 2007, 37 (1): 127-130.

[7] MA Qiu-zhu, HE zhi-min, CAI ze-ming, Engineering properties of diatomaceous in Namibia, Port \& Water way engineering, 1002-4972 (2017) 12-0080-05

[8] MA Yuan, The Structure, Composition and Their Engineering Implication of Diatomite in Zhejiang, Journal of Railway Engineering Society, 201936 (12) TU42 P642.1

[9] CHEN Zheng-han, GUO Nan. New developments of mechanics and application for unsaturated soils and special soils [J]. Rock and Soil Mechanics, 2019, 40 (1): 1-54

[10] Day, Robert W. Engineering Properties of Diatomaceous Fill $[\mathrm{J}]$. Journal of Geotechnical Engineers Division,American Society of Civil Engineers, 1995 (12): 908-910

[11] Tateishi Y. Geotechnical Properties of Diatom earth and stability of surface layer for the cut slpoe. Dotctoral Thesis, Saga University, 1997. 